\title{
THE PERIODONTAL CONDITION OF INSTITUTIONALIZED CHILDREN; IMPROVEMENT THROUGH ORAL HYGIENE*
}

\author{
By Edward D. Goyings, D.D.S., and Dick M. Riekse, D.D.S.*
}

If time and expense can be managed, the periodontal condition

of mongoloid children can be improved.

Periodontal disease in institutionalized children creates a troublesome problem. It is costly, both in terms of the residents' welfare and the clinical time necessary to treat the disease. The study by Cohen, et al., ${ }^{3}$ reported that periodontal disease was present in approximately 96 percent of institutionalized mongoloid children (Down's Syndrome), and approximately 40 percent of nonmongoloid children of the same institution. This report indicated that the problem was great. Other researchers, for example, Johnson and Young, ${ }^{6}$ and Swallow, ${ }^{14}$ reported comparable findings.

The periodontal conditions in the mongoloid children at Plymouth State Home and Training School, Northville, Michigan, have disturbed the Director of the Dental Department because of the time required for treatment. The Director's concern for these children initiated a project of research. It was planned through an intensified program of oral hygiene to attempt to decrease the prevalence and later the incidence of periodontal disease in a group of institutionalized residents, particularly the mongoloid children. It was planned, further, through an initial prophylaxis and 60 days of toothbrushing, twice daily, by two senior dental students of The University of Michigan to test the hypothesis which follows: A program of intensified oral hygiene will decrease comparably the severity and then the incidence of periodontal disease in both mongoloid and nonmongoloid institutionalized children.

\section{A. Review of Pertinent Literature}

The literature pertinent to the periodontal conditions of institutionalized children, particularly mongoloid children, has been reviewed to determine the following information: (1) the prevalence of periodontal disease in institutionalized children; (2) the factors which influence this prevalence; and (3) the effect of oral hygiene upon this prevalence.

\section{Prevalence of Periodontal Disease in Institutionalized Children}

Cohen, et al., ${ }^{3}$ in a study completed at Fernald State School, Waverly, Massachusetts, selected three groups for study with 100 patients in each group. One group consisted of mongoloid patients of the institution with a range in age of one to 30 years. The second group consisted of nonmongoloid patients of comparable ages. The third group consisted of the patients of a clinic of a dental school, again of comparable ages. These investigators reported that loss of alveolar bone was present in approximately 96 percent of the mongoloid chil-

\footnotetext{
* Summer project of research for senior dental students supported by U. S. Public Health Service Grant, GRS66, 39478.

* School of Dentistry, The University of Michigan, Ann Arbor 48104.
} 
dren and 40 percent of the nommongoloid children of the same institution. This loss of bone contrasted with a loss of 6.0 percent for the patients in the clinic of the dental school.

Johnson and Young, ${ }^{\text {ij }}$ in a study performed at Dixon State School in Illinois, randomly selected two study groups of comparable ages. One group consisted of 70 mongoloid residents while the other group consisted of 40 nonmongoloid mentally retarded residents. The investigators examined only the anterior teeth because of the lack of cooperation of the subjects. They reported a high percentage of periodontal disease in both groups. In the mongoloid study-group, 96 percent of the subjects were affected by periodontal disease while in the nonmongoloid study-group 87.5 percent of the subjects were affected.

\section{Factors Which Influence Periodontal Disease in Institutionalized Children}

The study by Cohen, et al.," reported certain characteristics which might possibly infuence the prevalence of periodontal disease in the mongoloid child. The factors which were reported follow: (1) macroglossia; (2) malocclusion associated with the typical mongoloid class III occlusion; (3) pegged teeth; and (4) the impaction of food.

Other factors which might influence the prevalence of periodontal disease in any institutionalized child also were reported: (1) lack of "dental care" and "oral hygiene"; (2) lack of routine prophylaxis; (3) lack of functional stimulation derived from normal mastication; (4) bruxism; (5) the presence of calculus; and (6) the presence of dental plaques.

Swallow ${ }^{14}$ stated that he had observed the possibility of tongue thrusting, mouth breathing, and the spacing of teeth as factors in the prevalence of periodontal disease in mongoloid children.

\section{Effect of Oral Hygiene}

In a study by Brown and Cunningham, ' a survey was made of the periodontal conditions of $80^{\circ}$ mongoloid patients who resided at the Levin Farm School, New Zealand. Of the 80 patients, 49 were under the age of 15 years. Brown and Cunningham stated that the formation of calculus was not common, and there was no correlation between the state of "oral cleanliness" and the periodontal disease present.

\section{B. Procedures of Current Study}

Because of the peculiarities inherent in a study of mentally retarded children, considerable study and experimentation had to be completed, prior to clinical activity, in order to gain objective measurements.

\section{Types of Patients}

The subjects selected for this study were male and female mentally retarded children from residents of buildings $B$ and $C$ at Plymouth State Home and Training School in Northville, Michigan. Initially 96 residents were selected, with equal numbers of males and females. The ages of the residents in this study varied from five years to 19 years. The mean age was nine years.

A few of the participating residents were eliminated during and at the completion of the study because they were "habitual ruminators," or they were not included in the final examination because of scheduling conflicts. This elimination reduced the total number of participants by eight-from 96 to 88 . Of the 88 residents who completed the study, 54 were mongoloid and 34 nonmongoloid children. The resulting percentages were 61.4 percent mongoloid and 38.6 percent nonmongoloid. 
The total participating sample was distributed among four wards at Ply. mouth State Home and Training School. This distribution is shown in the following table (Table 1).

\section{Table 1}

Age, Sex, and Etiological Distribution of Study Sample

$\begin{array}{ccccccc}\text { Bldg. } & \text { Ward No. } & \text { Age } & \text { Sex } & \text { Mongoloid } & \text { Nonmongoloid } & \text { Totals } \\ \text { B } & 1 & 6-12 & \text { M }+ \text { F } & 14 & 10 & 24 \\ \text { B } & 2 & 9-19 & \text { F } & 11 & 10 & 21 \\ \text { B } & 4 & 5-14 & \text { M F F } & 15 & 6 & 21 \\ \text { C } & 7,8 & 7-12 & \text { M } & 14 & 8 & \frac{22}{88} \\ \text { Totals } & & \frac{5-19}{19} & & 54 & -\frac{8}{34} & \end{array}$

\section{Formation of Study Groups}

Three study groups $A, B$, and $C$ were formed through selection of random numbers. Study-group A received mechanical toothbrushing; study-group B received manual toothbrushing; and study-group $C$ received the routine institutional care and served as the control. The following table (Table 2) shows the percentage distribution of the participa'ing residents within these three studygroups.

\section{Table 2}

Percentage Distribution of Mongoloid to Nonmongoloid Children in the

Study-Group

Mongoloid

Nonmongoloid

\section{Three Study-Groups}

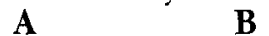

33.3

26.5
B

33.3

32.4

$\begin{array}{cc}\text { C } & \text { Total } \\ 33.3 & 100 \\ 41.1 & 100\end{array}$

\section{Recording and Scoring}

Evaluation of Indices. Other investigators have developed and used a wide variety of methods and criteria for evaluating the status of oral hygiene in populations. These methods were not completely applicable to this current study. Ramfjord ${ }^{11}$ has developed an index based on the use of six representative permanent teeth. Shick and Ash ${ }^{13}$ have altered Ramfjord's index in order to score separately the lingual and facial surfaces. Greene and Vermillion ${ }^{5}$ developed an Oral Hygiene Index based on the gross debris and calculus on permanent teeth in three segments of each dental arch.

None of these indices was utilized in this study for the following reasons:

(1) The lack of cooperation of many of the subjects because of their mental and physical capacities and their existing periodontal disease (Lack of cooperation made it impossible, from the initial experience of the investigators, for the examiner to measure periodontal pockets or apply disclosing solution. Johnson and Young, ${ }^{7}$ because of their experience, examined only the anterior teeth in the same type of patients.);

(2) The age of the subjects constituted a factor inasmuch as many had unerupted or impacted permanent teeth. (If often has been reported in the literature that mongoloid patients exhibit delayed eruption of their permanent teeth and have "irregular abnormal sets of teeth" as described by Oster (1953). ${ }^{16}$ The numerous dental anomalies of mongoloid patients were discussed in detail in Kisling's study. $\left.{ }^{15}\right)$; 
(3) Early loss of permanent teeth, primarily because of periodontal disease (Cohen, et al., ${ }^{3}$ and Johnson and Young ${ }^{7}$ both have reported severe loss of bone and early loss of the permanent teeth.);

(4) Physical stigmata somewhat characteristic of the mongoloid child (Johnson and Barnett ${ }^{6}$ have listed the frequent physical signs observed in mongoloid patients.).

Consideration of Criteria of Effectiveness. The most acceptable criteria of effectiveness are those which can be quantitated and can be scored repeatedly with a minimum of error. A sufficient number of criteria should be utilized to evaluate comprehensively the effectiveness of a program of oral hygiene. The criteria also should be related to the range expected in the condition being measured in the subjects and to the period of time in which the changes are expected to occur. Changes in plaque occur rapidly while those of periodontal condition occur much more slowly.

Indices for scoring plaque, gingivitis, and periodontal disease in epidemiological studies of mongoloid individuals have reflected little consideration of the calculus present. Johnson and Young ${ }^{-}$utilized the Russell Index ${ }^{12}$ in their study of the periodontal diseases in mongoloids, but could apply this index to the anterior part of the mouth only. Since the investigators found this same problem, they developed criteria which were applicable to the type of subject which they had to survey. Their definition of indices follows:

Plaque: plaque was scored and recorded as

P-0 Absence of dental plaque,

P-1 Slight amount of dental plaque-measured as covering the gingival third of the tooth on any of the facial, lingual, or interproximal surfaces,

P-2 Gross amount of dental plaque-measured as covering at least one-half of either the facial or lingual surfaces.

Calculus: calculus was scored and recorded as

C-() Absence of calculus,

C-1 Slight amount of supragingival calculus-measured as covering less than one-third of the surfaces from the free gingival margin of the teeth,

C-2 Gross amount of calculus either supragingival, subgingival, or a combination of both-measured as covering greater than one-third of the surfaces from the free gingival margin of the teeth.

Periodontal Condition: periodontal condition was scored and recorded as

G-0 No gingivitis,

G-1 Marginal gingivitis,

G-2 Gingivitis with ulceration and a great tendency to bleed,

G-3 Gingivitis with pockets,

G-4 Gingivitis with ulceration and pockets (a combination of G-2 and G-3).

\section{Details of Scoring}

(1) Plaque: Only plaque which was visible to the eye on the facial or lingual surfaces was scored (an SSWV No. 5 explorer was used for detecting interproximal plaque).

(2) Calculus: The recording of calculus was based on its presence visually or by probing subgingivally with the SSW No. 5 explorer.

(3) Periodontal Condition: The instruments used to obtain these scores were an SSW No. 5 explorer and a mouth mirror. 


\section{Clinical Procedures}

After the sample of participants was selected and the groups were formed, all of the residents were examined and scored by a separate, unbiased examiner. A complete prophylaxis was performed, by the two investigators, following the scoring, for all participating residents. After the prophylaxis, the investigators brushed the teeth of the residents in the experimental groups twice per day, after breakfast and after lunch, and continued the brushing for a period of 60 days. The controls continued to receive routine institutional care, which appeared to consist of toothbrushing that ranged from two times per day to no toothbrushing at all. In the beginning, all old brushes were discarded and each resident was assigned a new brush.

The investigators alternated between groups A (mechanical brushing) and B (manual brushing) and between the wards to neutralize any differences between the performances of the two investigators. A "Scrub-brush"method was employed to simulate that used by attendants. At the end of the 60 days of toothbrushing, the participating residents were reexamined and scored by the original, unbiased examiner.

\section{Types of Brushes and Dentifrice}

Two types of brushes were used in this study-the Broxodont automatic toothbrush and a multitufted manual toothbrush of standard design. The Broxodont's "heads" were of medium-hard nylon bristles, three rows wide and five tufts per row, alternating in length, and with approximately 100 bristles per tuft. The manual brushes were of medium nylon bristles, three rows wide, nine tufts in length, and with 27 bristles per tuft. They were made in Jackson State Prison (Michigan). The manual brushes had a straight handle. Both of these brushes were used because they were the type already in use at this institution.

The dentifrice used (Craig-Martin) was slightly abrasive and had stannous fluoride added. This dentifrice also was the one used most frequently at this institution.

\section{Findings in the Study}

\section{Prevalence of Periodontal Disease}

Table 3 indicates, at the time of the initial examination, that both groups (mongoloid 100 percent and nonmongoloid 95 percent) were affected to some degree by periodontal disease. The periodontal disease was more severe in the mongoloid than in the nonmongoloid children (49.61 percent mongoloid in G-2 through G-4 compared to 7.50 percent of the nonmongoloid).

\section{Table 3}

Periodontal Conditions of Mongoloid and Nonmongoloid Children at Initial Examination

36 Mongoloid 20 Nonmongoloid Periodontal Condition:

$\begin{array}{lcc} & \text { (Percent) } & \text { (Percent) } \\ \text { G-0 } & 0.00 & 5.00 \\ \text { G-1 } & 51.39 & 87.50 \\ \text { G-2 } & 4.17 & 7.50 \\ \text { G-3 } & 22.22 & 0.00 \\ \text { G-4 } & 22.22 & 0.00\end{array}$

G-0 No gingivitis

G-1 Marginal gingivitis

G-2 Gingivitis with ulceration and great tendency toward bleeding

G-3 Gingivitis with pockets

G-4 Gingivitis with ulceration and pockets (a combination of G-2 and G-3) 


\section{Effect of Oral Hygiene on Dental Plaque}

Table 4 indicates that the presence of dental plaque, at the initial examination, for both the mongoloid and nonmongoloid experimental groups was essentially equal. At the final examination, the presence of dental plaque in both experimental groups was significantly reduced while the presence of dental plaque in the controls remained relatively constant.

Table 4

Scores of Plaque of Mongoloid and Nonmongoloid Children at Initial and Final Examination

\begin{tabular}{|c|c|c|c|c|c|c|c|c|}
\hline & \multicolumn{4}{|c|}{54 Mongoloid } & \multicolumn{4}{|c|}{34 Nonmongoloid } \\
\hline & \multicolumn{2}{|c|}{$\begin{array}{c}36 \text { Experimental } \\
\text { Percentages }\end{array}$} & \multicolumn{2}{|c|}{$\begin{array}{l}18 \text { Controls } \\
\text { Percentages }\end{array}$} & \multicolumn{2}{|c|}{$\begin{array}{l}20 \text { Experimental } \\
\text { Percentages }\end{array}$} & \multicolumn{2}{|c|}{$\begin{array}{l}14 \text { Controls } \\
\text { Pcrcentages }\end{array}$} \\
\hline & $\begin{array}{c}\text { Initial } \\
\text { Exam }\end{array}$ & & & & & & & $\begin{array}{l}\text { Final } \\
\text { Exam }\end{array}$ \\
\hline$P-0$ & 0.00 & 25.00 & 0.00 & 0. & 0.00 & 20.00 & 0.00 & 0.00 \\
\hline P-1 & 72.22 & 75.00 & 47.22 & 50.0 & 77.50 & 77 & 82.14 & 75.00 \\
\hline P-2 & 27.78 & 0.00 & 52.78 & 50.00 & 22.50 & 2.50 & 17.86 & 25.0 \\
\hline
\end{tabular}

P-0 Absence of dental plaque

P-1 Slight amount of dental plaque (covering the gingival third of the tooth on either the facial or lingual and/or the interproximal surfaces)

P-2 Gross amount of dental plaque (covering at least one-half of either buccal or lingual surfaces)

\section{Effect of Oral Hygiene on Calculus}

Table 5 indicates that both mongoloid and nonmongoloid experimental groups evidenced a significant decrease in the amount of calculus present upon final examination. Both the mongoloid and nonmongoloid controls, however, did experience some decrease in the amount of calculus, although it was not significant.

Table 5

Scores of Calculus of Mongoloid and Nonmongoloid Children at Initial and Final Examination

\begin{tabular}{|c|c|c|c|c|c|c|c|c|}
\hline & \multicolumn{4}{|c|}{54 Mongoloid } & \multicolumn{4}{|c|}{34 Nonmongoloid } \\
\hline & \multicolumn{2}{|c|}{$\begin{array}{l}36 \text { Experimental } \\
\text { Percentages }\end{array}$} & \multicolumn{2}{|c|}{$\begin{array}{l}18 \text { Controls } \\
\text { Percentages }\end{array}$} & \multicolumn{2}{|c|}{$\begin{array}{l}20 \text { Experimental } \\
\text { Percentages }\end{array}$} & \multicolumn{2}{|c|}{$\begin{array}{l}14 \text { Controls } \\
\text { Percentages }\end{array}$} \\
\hline & Initial & Final & Initial & Final & Initial & Final & Initial & Final \\
\hline & Exam & Exam & Exam & Exam & Exam & Exam & Exam & Exam \\
\hline-0 & 19.44 & 75.00 & 5.56 & 22.22 & 5.00 & 50.00 & 14.28 & 21.42 \\
\hline-1 & 73.37 & 25.00 & 94.44 & 72.22 & 85.00 & 50.00 & 75.00 & 71.42 \\
\hline $\mathrm{C}-2$ & 4.17 & 0.00 & 0.00 & 5.56 & 10.00 & 0.00 & 10.71 & 7.14 \\
\hline & \multicolumn{8}{|c|}{ Absence of calculus } \\
\hline & \multicolumn{8}{|c|}{$\begin{array}{l}\text { Slight amount of supragingival calculus covering less than one-third of the } \\
\text { surfaces of the teeth from the free gingival margin }\end{array}$} \\
\hline-2 & \multicolumn{8}{|c|}{$\begin{array}{l}\text { Gross amount of calculus either supragingival, subgingival or a combination } \\
\text { of both covering greater than one-third of the surfaces of the teeth from } \\
\text { the free gingival margin }\end{array}$} \\
\hline
\end{tabular}




\section{Effect of Oral Hygiene on Periodontal Condition}

The periodontal condition of the mongoloid and nonmongoloid child at the initial examination and final examination is shown in Table 6. The periodontal condition of the mongoloid experimental group improved significantly while that of the mongoloid controls appeared to deteriorate. The periodontal condition of the nonmongoloid experimental group also improved significantly (5.00 percent had no gingivitis at the initial examination compared with 70 percent without gingivitis at the final examination). The nonmongoloid controls remained relatively stable.

Table 6

Scores for Periodontal Condition of Mongoloid and Nonmongoloid Children at Initial and Final Examination

\begin{tabular}{|c|c|c|c|c|c|c|c|c|}
\hline \multicolumn{5}{|c|}{54 Mongoloid } & \multicolumn{4}{|c|}{34 Nonmongoloid } \\
\hline & \multicolumn{2}{|c|}{$\begin{array}{c}36 \text { Experimental } \\
\text { Percentages }\end{array}$} & \multicolumn{2}{|c|}{$\begin{array}{l}18 \text { Controls } \\
\text { Percentages }\end{array}$} & \multicolumn{2}{|c|}{$\begin{array}{c}20 \text { Experimental } \\
\text { Percentages }\end{array}$} & \multicolumn{2}{|c|}{$\begin{array}{l}14 \text { Controls } \\
\text { Percentages }\end{array}$} \\
\hline & $\begin{array}{l}\text { Initial } \\
\text { Exam. }\end{array}$ & $\begin{array}{l}\text { Final } \\
\text { Exam. }\end{array}$ & $\begin{array}{l}\text { Initial } \\
\text { Exam. }\end{array}$ & $\begin{array}{l}\text { Final } \\
\text { Exam. }\end{array}$ & & $\begin{array}{c}\text { Final } \\
\text { Exam. }\end{array}$ & $\begin{array}{l}\text { Initial } \\
\text { Exam. }\end{array}$ & $\begin{array}{c}\text { Final } \\
\text { Exam }\end{array}$ \\
\hline $3-0$ & 0.00 & 22.22 & 0.00 & 0.00 & 5.00 & 70.00 & 14.29 & 21.43 \\
\hline & & & & & & & & 64.25 \\
\hline G-2 & 4.17 & 4. & 8.33 & 11 & 7.50 & 0.00 & 10.71 & 0.00 \\
\hline $3-3$ & 22.22 & 8.3 & 27.7 & & 0. & 0.00 & 0.00 & \\
\hline G-4 & 22.22 & 0.00 & 19.44 & 30.56 & 0.00 & 0.00 & 10.71 & 7.14 \\
\hline
\end{tabular}

G-0 No gingivitis

G-1 Marginal gingivitis

G-2 Gingivitis with ulceration and great tendency toward bleeding

G-3 Gingivitis with pockets

G-4 Gingivitis with ulceration and pockeis (a combination of G-2 and G-3)

Table 7

Periodontal Condition; Scores of Mongoloid and Nonmongoloid Experimental Groups Compared at Initial and Final Examination

\begin{tabular}{|c|c|c|c|c|}
\hline & $\begin{array}{l}36 \text { Mongoloid } \\
\text { Percentages }\end{array}$ & $\begin{array}{l}20 \text { Nonmongoloid } \\
\text { Percentages }\end{array}$ & $\begin{array}{c}36 \text { Mongoloid } \\
\text { Percentages }\end{array}$ & $\begin{array}{l}20 \text { Nonmongoloid } \\
\text { Percentages }\end{array}$ \\
\hline & $\begin{array}{l}\text { Initial } \\
\text { Exam. }\end{array}$ & $\begin{array}{l}\text { Initial } \\
\text { Exam. }\end{array}$ & $\begin{array}{l}\text { Final } \\
\text { Exam. }\end{array}$ & $\begin{array}{l}\text { Final } \\
\text { Exam. }\end{array}$ \\
\hline $\mathrm{G}-0$ & 0.00 & 5.00 & 22.22 & 70.00 \\
\hline G-1 & 51.39 & 87.50 & 65.28 & 30.00 \\
\hline G-2 & 4.17 & 7.50 & 4.17 & 0.00 \\
\hline G-3 & 22.22 & 0.00 & 8.33 & 0.00 \\
\hline G-4 & 22.22 & 0.00 & 0.00 & 0.00 \\
\hline
\end{tabular}

G-0 No gingivitis

G-I Marginal gingivitis

G-2 Gingivitis with ulceration and great tendency toward bleeding

G-3 Gingivitis with pockets

G-4 Gingivitis with ulceration and pockets (a combination of G-2 and G-3) 


\section{Periodontal Condition; Mongoloid Versus Nonmongoloid}

The periodontal condition of the mongoloid experimental group, compared to the condition of the nonmongoloid experimental group at the initial examination and at the final examination is shown in Table 7. Both experimental groups improved significantly, although the improvement of the mongoloid group was not as great quantitatively or qualitatively as for the nonmongoloid group.

\section{Discussion and Appraisal of Information Gathered}

\section{Prevalence}

The information presented in the review of the pertinent literature indicated that prevalence of periodontal disease was high among institutionalized children.

Cohen, et al., ${ }^{3}$ in a study of institutional subjects, reported a loss of alveolar bone in 96 percent of mongoloid as compared with 40 percent of nonmongoloid subjects. The results were derived from an examination of radiographs.

Johnson and Young," in their study of institutional subjects, limited their examination to the anterior teeth. They reported the clinical prevalence of periodontal disease in institutionalized mongoloid patients to be 96 percent compared with 87 percent of the nonmongoloid subjects.

Table 3 shows that 100 percent of the mongoloid and 95 percent of the nonmongoloid subjects initially were affected by periodontal disease. The percentages found obviously were greater than the percentages of the previous investigators. Possibly this difference evolved from differences in the criteria for scoring. The greater percentage in prevalence found in the present study may represent a more comprehensive periodontal evaluation. Although periodontal disease was present in a significant percentage in both mongoloid and nonmongoloid subjects, the mongoloid child apparently exhibited a more severe form of periodontal disease (Table 3).

Many factors may influence periodontal disease in institutionalized children. Other investigators ${ }^{1,},{ }^{14}$ have observed and studied these adverse factors. Some of these local factors are poor oral hygiene, habits (bruxism and mouthbreathing), nondetergent semi-solid diets, and the lack of cooperation observed in practically all of these children. Local factors such as macroglossia, malocclusion, "pegged" teeth, spacing of teeth, delayed eruption of teeth, and early loss of permanent teeth can be observed in both mongoloid and nonmongoloid children, but they appear to be more prevalent in the mongoloid children.

\section{Effect of Program of Oral Hygiene}

Few studies have been reported of the effect of oral hygiene on the periodontal conditions of institutionalized children. In a study by Brown and Cunningham, ${ }^{1}$ a survey was made of 80 mongoloid patients. These investigators summarized: "Calculus formation was not common and there was no correlation between the state of 'oral cleanliness' and the periodontal disease present." Referring to Table 4 , it can be noted that dental plaque initially was present in 100 percent of both mongoloid and nonmongoloid groups. Calculus initially was present in at least 77.54 percent of the mongoloid group (Table 5). These data appear to contradict the summarizations of Brown and Cunningham's ${ }^{1}$ survey. After a 60-day period of intensified oral hygiene, the amounts of local irritants were reduced significantly. At the time of the initial examination, all subjects in both mongoloid and nonmongoloid experimental groups exhibited a significant decrease in the amount of dental plaque while the controls remained relatively the same (Table 4). 
The scores indicate initially that a significant percentage of both the mongoloid and nonmongoloid experimental groups exhibited calculus. Both mongoloid and nonmongoloid experimental groups experienced a significant decrease in the amount of calculus present after the program of oral hygiene. Both the mongoloid and nonmongoloid controls, however, did experience some decrease in the amount of calculus (Table 5). The apparent decrease in the amount of calculus in the controls might be ascribed to the effect of the initial prophylaxis which all of the participants received.

The most significant finding in the study was the effect of the program of oral hygiene upon the periodontal condition. The scores showed that the periodontal condition of the mongoloid experimental group inproved significantly while that of the mongoloid controls deteriorated. The periodontal condition of the nonmongoloid experimental group also improved significantly while the nonmongoloid controls remained relatively the same (Table 6).

Initially, 51.39 percent of the mongoloid experimental group exhibited marginal gingivitis and the remainder exhibited a more severe periodontal condition. Periodontal pockets were exhibited by 44.44 percent of this remainder. Additionally, 26.39 percent exhibited gingivitis with ulceration either by itself or superimposed on periodontal pockets. Compared with the mongoloid group upon initial examination, 87.5 percent of the nonmongoloid group exhibited marginal gingivitis while none exhibited periodontal pockets. Only 7.5 percent exhibited gingivitis with ulceration (Table 7).

After the program of oral hygiene the periodontal condition of both the mongoloid and nonmongoloid experimental groups improved significantly. The mongoloid experimental group, however, apparently did not respond as well as the nonmongoloid experimental group. It may be suggested that a reason for this difference was that a large percentage of mongoloid children initially exhibited periodontal pockets.

\section{The Analysis of Data}

In an attempt to analyze the data obtained from the two examinations, it became obvious that the method of multiple comparisons could not be utilized because of the lack of independence of factors (wards, methods of brushing, mongols, nonmongols). Since 60 percent of the "cells" into which the subjects had to be classified, were under five in expected number, the $\mathrm{X}^{2}$ method of analysis could not be used to test significance (See Table No. 6). Study of the data obtained indicated that the group of subjects might have to be enlarged to approximately five times the number studied in order to gain data which could be analyzed for significance by the method of $\mathrm{X}^{2}$.

The expression of the findings in percentages, on the other hand, did indicate an obvious significant improvement in oral conditions.

\section{Some Recommendations}

(1) It may be suggested that an intensified program of oral hygiene be implemented immediately for the oral well-being of such institutionalized children.

(2) Apparently the nonmongoloid benefited more from this program of oral hygiene than the mongoloid group. A program of longer duration might benefit the mongoloid group much more, and such a program should be initiated.

(3) To gain additional benefit, it may be suggested that a program of hygiene should be directed primarily at the younger institutionalized child, perhaps 3-12 years of age. 
(4) Since the total sample studied was found to be too small for analysis by the method of $\mathrm{X}^{*}$, another study should be initiated for a group of subjects approximately five times in size (440).

(5) Inasmuch as histories of the residents are available which include physical, mental, psychological, sociological and genetic information, some thought should be given to a study of related factors.

(6) The indices used in this study should be tested on a large group of children for adequacy and reproducibility.

(7) Sufficient calibration of the independent examiner should precede each examination (initial and final).

\section{E. Summary}

A comparison of the effect of a program of intensified oral hygiene was made on 88 institutionalized children at Plymouth State Home and Training School, Northville, Michigan. All participating residents received an initial prophylaxis prior to the 60 days of toothbrushing. Two comparable groups were formed of 54 mongoloid and 34 nonmongoloid children. Of the 54 mongoloid children, 36 received toothbrushing twice a day, for 60 days. The remaining 18 received routine institutionalized care and served as controls. Of the 34 nonmongoloid children, 20 received toothbrushing twice a day for 60 days. The remaining 14 received routine institutional care and also served as controls.

The participating residents were scored by an independent examiner for dental plaque, calculus, and the periodontal condition both before and after the 60 davs of toothbrushing.

Evaluation of the scores indicated a decrease in the severity and prevalence of periodontal disease in both the mongoloid and nonmongoloid institutionalized children on a comparable basis.

\section{F. Conclusions}

Within the limits of this study, the following conclusions can be submitted: (1) following a program of oral hygiene (toothbrushing), periodontal disease in both mongoloid and nonmongoloid institutionalized children was decreased significantly; and (2) the percentage of decrease was greater in the nonmongoloid children.

\section{Bibliography}

1. Brown, R. H., and Cunningham, W. H. Some dental manifestations of mongolism. Oral Surg., Oral Med. and Oral Path., 14:64-76, June 1961.

2. Cohen, B. H., Lilienfeld, A. M., and Sigler, A. T. Some epidemiologic aspects of mongolism: a review. Am. J. Pub. Health., 53:223-36, Feb. 1963

3. Cohen, M. M., et al. Oral aspects of mongolism. Part I. Periodontal disease in mongolism. Oral Surg., Oral Med. and Oral Path., 14:92-107, Jan. 1961.

4. Coldman, A. S. Predisposing genetic and metabolic factors to developmental defects of the CNS, P. 63-74. (In the child with CNS deficit; report of two symposiums. No. 432, Washington, U. S. Children's Bureau, 1965. 149P.)

5. Greene, J. C., and Vermillion, I. R. Oral hygiene index: a method for classifying oral hygiene status. Am. Dent. A. J., 61:172-9, Ang. 1960.

6. Johnson, C. D., and Barnet, C. D. Relationship of phrsical stigmata to intellectual status in mongoloids. Am. J. Ment. Deficiency, 66:435-7, Nov. 1961.

7. Johnson, N. P., and Young, M. A. Periodontal clisease in mongols. J. Periodont., 34:41-7, Jan. 1963.

8. Kaariainen, R., and Dingman, H. F. The relation of the degree of mongolism to the degree of subnormality. Am. J. Ment. Deficiency, 66:438-43, Nov. 1961.

9. Levinson, Abraham, Friedman, Abraham, and Stamps, Frederick. Variability of nongolism. Pediatrics, 16:43-52, July 1955. 
10. Ramfjord, S. P. Bruxism; a clinical and electromyographic study. Am. Dent. A. J., 62:20-44, Jan. 1961.

11. ....... Indices for prevalence and incidence of periodontal disease. J. Periodont., 30:51-9, Jan. 1959 .

12. Russell, A. L. A system of classification and scoring for prevalence surveys of periodontal disease. J. Dent. Res., 35:350-9, June 1956.

13. Shick, R. A., and Ash, M. M. Evaluation of the vertical method of toothbrushing. J. Periodont., 32:346-53, Oct. 1961.

14. Swallow, J. N. Dental disease in children with Down's Syndrome. J. Ment. Deficiency Res., 8:102-18, Dec. 1964.

15. Kisling, Erik. Cranial morphology in Down's Syndrome; a comparative roentgencephalometric study in adult males. Copenhagen, Munksgaard, 1966. 107P.

16. Oster, Jacob. Mongolism. Copenhagen, Danish Science Press, 1953. 205p.

\section{Toxic Effects}

Reports Dr. Yngve Ericcson, of Stockholm's Dental School, a survey of the world's reports of clinical and epidemiological studies of the ingestion of small amounts of fluoride by human beings, and experimentation with animals shows not one scientifically demonstrated instance of damage to health. Reports of allergy to the $\mathrm{F}$ in human beings must be regarded as inaccurate, since allergy is unknown among the world's billions of consumers of F-rich tea, and the statements of damage from drinking fluoridated water in concentrations up to 1.0 to 2.0 p.p.m. of $F$ are contradicted by well-established scientific data. (British Dental Journal, for September 19, 1967)

\section{A Geriatric Birthday?}

Be reminded that the National Institutes of Health reached a respectable geriatric maturity of 80 years in 1967. As a common geriatric symptom, this complex, founded as a one-room laboratory at Staten Island Marine Hospital in 1887 , has taken on girth. Its 300-acre campus in Bethesda, Maryland, now houses 50 buildings that provided 36 percent of the Nation's expenditures for dental and medical research in 1967 and vigorously administered a budget of slightly over $\$ 1.1$ billion. Whenever the final history of improvement of health in the United States is written, it must contain a glowing statement of gratitude from American dentists. (Journal of the American Dental Association for November, 1962)

\section{Fluoride-Supplements}

Canada's Council on Dental Research concludes, from the standpoint of the public's health, that "home-administration of fluoride is not a dependable substitute for the communal fluoridation of drinking water." This conclusion is based on evidence that home-administration requires an extensive period of exacting and intelligent cooperation in the individual household. (Journal of the Canadian Dental Association for September, 1967) 